\title{
COPARENTING IN THE DIGITAL ERA: EXPLORING DIVORCED PARENTS' USE OF TECHNOLOGY
}

\author{
Jodi Dworkin, Ellie McCann and \\ Jenifer K. McGuire
}

\begin{abstract}
Purpose - The current study was designed to examine how and why divorced parents use computers and the Internet for communication with their coparent and with their child(ren).

Methodology/approach - The current study utilized the uses and gratification perspective. A subsample of 178 divorced parents with at least one child aged 25 or younger from a larger research project participated. Parents were recruited to participate in a 15-minute online survey through email listservs with a nationwide and demographically diverse reach.

Findings - Analyses revealed that divorced parents are active users of technology, for communicating with their child(ren) as well as with the child(ren)'s other parent. In addition, parents were comfortable using the Internet and accessing online parenting information, citing few barriers to use.
\end{abstract}

\footnotetext{
Divorce, Separation, and Remarriage: The Transformation of Family Contemporary Perspectives in Family Research, Volume 10, 279-298 Copyright (C) 2016 by Emerald Group Publishing Limited All rights of reproduction in any form reserved ISSN: 1530-3535/doi:10.1108/S1530-353520160000010011
} 
Research limitations/implications - We did not capture the reasons for communicating or the content of communication. Future research should use innovative methodologies and measures to better understand the use of specific technologies and tools to negotiate boundaries between coparents living apart. In addition, a larger, more diverse sample might reveal different patterns of divorced parents' technology use.

Practical implications - Technology allows for asynchronous communication, staying up to date, making plans, and making decisions with minimal interaction, and thus maintaining boundaries. Our evidence suggests technology could help parents find areas of agreement around their children's lives in a less contentious environment.

Originality/value - This study provides the essential groundwork for further examination of ways to support coparent communication via technology.

Keywords: Divorce; coparenting; technology; parenting; Internet

Approximately 21 million children, or roughly $28 \%$ of children in the United States, were living with one parent in 2012 (Vespa, Lewis, \& Kreider, 2013). The courts are increasingly awarding joint legal and physical custody following divorce, to allow children continued access to both parents. However, this means that coparents must collaborate to make decisions about their children, and share parenting responsibilities while living in different households (Ahrons, 2007; Miller, 2009). Being able to communicate well is important for divorced coparents. The quality of the coparental relationship is related to the well-being of the children and the parents (Buchanan, Maccoby, \& Dornbusch, 1996; Sandler, Miles, Cookston, \& Braver, 2008). Communication in particular has been identified as a factor that may facilitate or hinder postdivorce familial relationships (e.g., Afifi \& McManus, 2006).

The frequent use of technology for communication among adults suggests that consideration of the use of new media and online activities is critical for facilitating coparent and parent-child communication. Research on technology use in parent-child relationships has focused on adolescent use and parental monitoring of adolescent technology use (Lee \& Chae, 2007; Subrahmanyam \& Greenfield, 2008; Ybarra \& Mitchell, 2004). The limited research on technology use and parenting (Dworkin, Connell, \& Doty, 2013) and technology use in families has largely ignored family 
structure (Chapman, Ganong, \& Coleman, 2015). Specifically, we know little about how divorced coparents are using technology to communicate with each other or with their child(ren). The present exploratory study is designed to address this gap by considering divorced coparents use of technology to communicate with the other parent and with their child(ren), while also taking into account their comfort with and attitudes toward technology.

\section{CONCEPTUAL FRAMEWORK}

The uses and gratification perspective focuses on individuals' purposive and goal directed media use. One assumption of this perspective is that the use of media tools competes with other resources to fill one's gratifications (Grant, 2005); and thus, individuals actively choose media to gratify their needs (Rubin, 2002). Gratifications, based in social roles and contexts, are the desires and needs users have that motivate them to use certain media (Rubin, 2002), for example like staying connected to a coparent for the benefit of the child and staying connected with the child when he or she is with the coparent. The social context parents operate in can influence their patterns of use and gratification. In the current study, the uses and gratification perspective can improve our understanding of divorced parents' use of online tools. For instance, utility may affect divorced parents' use of online tools; parents who expect to benefit from a particular online communication method to avoid conflict with a coparent will be more likely to use that method (Ruggiero, 2000). The current study utilizes the uses and gratification perspective to consider how divorced parents use technology to connect with their coparent and their child(ren). For researchers and educators to develop technology-based resources and educational opportunities, it is important to better understand how divorced coparents are using technology and the possible barriers to use.

\section{COMMUNICATION VIA TECHNOLOGY IN DIVORCED FAMILIES}

After divorce, many coparents need to have regular communication regarding the day-to- day needs of their children. Coparents report that they communicate through technology, an often preferred method of communication, 
to avoid the conflict of face-to-face or verbal phone discussions when there is a need to communicate with the other parent over child-related issues (Ganong, Coleman, Feistman, Jamison, \& Markham, 2012). Some initial studies suggest that divorced parents use texting for day-to-day updates and reserve email for planning and discussing bigger issues that need parental consensus (Odom, Zimmerman, \& Forlizzi, 2010). There are currently several technology-based programs to help coparents with shared calendars that have proven helpful for parents to make decisions regarding involvement in activities and supporting positive perceptions of the other parent, but can have the risk of reducing privacy (Odom et al., 2010).

Coparents who believe that interacting with the other parent about child-related decisions will benefit both themselves and their child are more likely to engage in communication (Ganong, Coleman, Markham, \& Rothrauff, 2011), and report similar messages in face-to-face and technology supported modes (Laliker \& Lannutti, 2014). There is limited research on divorced parent's use of technology to communicate with their children when unable to connect in person. However, preliminary evidence suggests parents may be trying to hide communications with the child from the other parent (Saini, Mishna, Barnes, \& Polak, 2013). Findings are mixed, some fathers report enjoying the ability to connect virtually while others resented the fact that they perhaps felt forced into virtual parenting. Other studies have found that use of Skype and FaceTime are particularly useful when parent and child want to maintain their relationship when they are not physically together (Wolman \& Pomerance, 2012). In addition, there are gender differences. Mothers often report being managers of the coparenting team, deciding and managing who should play what roles in parenting their children. They viewed themselves as having primary responsibility for their children, with their children's fathers as important coparenting partners (Ganong, Coleman, Jamison, \& Feistman, 2015).

Rodriguez (2014) focuses on the importance of maintaining day-to-day communication, particularly around mundane topics, as a way to improve and sustain relationships. When parents are not able to have mundane conversations with their children, it is harder to "know" their children and maintain close relationships. Research on mundane talk exists in the peer relationships (e.g., Goldsmith \& Baxter, 1996) and intimate relationships (e.g., Alberts, Yoshimura, Rabby, \& Loschiavo, 2005) literature, yet mundane talk has not been well explored in the parent-child relationship. One notable exception describes the different roles of daily communication among stepfamilies, with recapping the events of the day as an important piece in maintaining and managing stepfamily relationships. Technology 
was a means to improve the day-to-day nature of communication among parents and children while still maintaining inter-parental boundaries. Technology also provided a way for nonresidential parents to communicate with the residential parent (Schrodt et al., 2007).

In addition to the need for communication, it is essential to explore the fit between parents and technology. Demographic differences, importance of comfort, how comfortable the other parent is with technology, and empathy and understanding for the other parents' technology use sets expectations for the coparent's response time, for example, and how engaged they may be via technology.

\section{TECHNOLOGY TO SUPPORT RELATIONSHIP MAINTENANCE}

Parents with high levels of communication and cooperation use a coparenting strategy referred to as cooperative coparenting (Maccoby, Depner, \& Mnookin, 1990). Three additional styles of coparenting have been identified by Maccoby and colleagues, and have relevance to parents' level of communication and engagement with each other. Disengaged coparenting is characterized by low levels of communication and cooperation between parents. Conflicted coparenting is characterized by a high level of communication that is conflict based with little cooperation. Mixed coparenting is characterized by high levels of conflictual communication. Parents exhibiting a mixed coparenting or a conflicted coparenting pattern have been shown to have parental conflicts that are witnessed by their children (Maccoby et al., 1990); as a result, these two groups of parents may have the greatest benefit of using asynchronous technology for communication between parents (Yarosh, Chieh, \& Abowd, 2009). Asynchronous communication is one-way parents can avoid having children witness conflict, but also gives parents the ability to regulate their emotions and responses to the other parent in their own space. In a very similar categorization, Beckmeyer, Coleman, and Ganong (2014) identified three types of coparenting relationships: cooperative and involved, moderately engaged, and infrequent but conflictual. Parents who are cooperative tend to use technology in cooperative ways to support their coparent relationship; coparents who are not cooperative use technology in harmful ways that may further break down the coparent relationship (Chapman et al., 2015).

Yarosh et al. (2009) examined technology use in post separation households, during a time when fewer technological supports were available to 
maintain contact and enhance communication. They focused on phone conversations as a means to maintain contact between parents and children while apart, as well as to facilitate collaboration among coparents, while allowing each parent to maintain autonomy. They discuss the need for enhanced technologies to improve communication opportunities between coparents who live apart, as well as between children and parents who are not together. Specifically, Yarosh et al. discuss particular types of technologies that can help to improve communication without interfering with parental autonomy. One specific approach they recommend is to improve upon asynchronous communication strategies that allow people to send a message without the need for immediate response or contact. New media tools such as text message, and instant message would serve this purpose.

\section{METHOD}

This study utilized a subsample of parents from a larger study which was designed to gain a better understanding of the ways in which and the reasons that parents use technology. Parents were recruited to participate in a 15-minute online survey through email listservs that reach a nationwide and demographically diverse sample, including National Institute of Food and Agriculture, Cooperative Extension, eXtension, state Department of Education, and other statewide and national networks that reach families and professionals with parenting resources. Potential participants were directed to a website to learn more about the project and complete the online survey. Participants could choose to be entered into a drawing for a gift card after completing the survey. One thousand six hundred and fiftythree parents participated in this study between May and November 2010.

\section{PARTICIPANTS}

A subsample was selected for the current study. To be eligible to participate, parents needed to indicate they were divorced and had at least one child age 25 years or younger. A total of 178 divorced parents were included in the current study (see Table 1). Over half of parents $(51.7 \%)$ lived in a suburban area, 49 parents $(27.5 \%)$ lived in a rural area, and 37 parents $(20.8 \%)$ lived in an urban area. The majority of parents $(97.8 \%)$ reported English as the primary language spoken in their home. 
Table 1. Demographic Information.

\begin{tabular}{|c|c|c|c|}
\hline & & $N$ & $\%$ \\
\hline \multirow[t]{5}{*}{ Age } & $20-29$ & 10 & $5.7 \%$ \\
\hline & $30-39$ & 36 & $20.5 \%$ \\
\hline & $40-49$ & 69 & $39.5 \%$ \\
\hline & $50-59$ & 55 & $31.4 \%$ \\
\hline & $60-64$ & 5 & $2.9 \%$ \\
\hline \multirow[t]{2}{*}{ Gender } & Male & 23 & $12.9 \%$ \\
\hline & Female & 155 & $87.1 \%$ \\
\hline \multirow[t]{2}{*}{ Race/Ethnicity } & Parents of color & 23 & $12.9 \%$ \\
\hline & White or Caucasian & 144 & $80.9 \%$ \\
\hline \multirow[t]{4}{*}{ Income } & Less than $\$ 30,000$ & 40 & $22.5 \%$ \\
\hline & $\$ 30,000-$ under $\$ 50,000$ & 42 & $23.6 \%$ \\
\hline & $\$ 50,000$ - under $\$ 75,000$ & 50 & $28.1 \%$ \\
\hline & $\$ 75,000-\$ 100,000$ or more & 33 & $18.5 \%$ \\
\hline \multirow[t]{3}{*}{ Education } & Less than college & 58 & $32.6 \%$ \\
\hline & College graduate & 56 & $31.5 \%$ \\
\hline & Postgraduate training, professional school, Master's, PhD & 64 & $36.0 \%$ \\
\hline
\end{tabular}

Three-quarters of parents $(74.7 \%)$ had one or two children (mean age of youngest child $=12.6$ years). Nearly three-quarters of parents $(74.2 \%)$ worked full time.

\section{MEASURES}

In addition to demographic information, parents were asked whether they used any of 14 technological devices (Allen \& Rainie, 2002; Blackburn \& Read, 2005) and how often they engaged in 17 new media and online activities and the purpose of those online activities.

New Media and Online Activities in General and Specifically for Parenting

Parents were asked how often they engaged in 17 new media and online activities in general. Participants who reported engaging in an activity 
received a follow-up question that asked how often they engaged in the activity specifically for parenting (see Table 2). Parenting was defined for parents as "all things you do to take care of your children and support their growth and development." Participants reported the frequency they performed each activity for parenting using a seven-point Likert-scale $(1=$ Never, 7 = Several times a day).

Table 2. Frequency of Parents' Use of New Media and Online Activities $(N=178)$.

\begin{tabular}{lcc}
\hline Activity $^{\mathrm{a}}$ & $\begin{array}{c}\text { In General } \\
\text { M(SD) }\end{array}$ & $\begin{array}{c}\text { For Parenting }^{\mathrm{b}} \\
\text { M(SD) }\end{array}$ \\
\hline Send or read email & 4.85 & 3.71 \\
Look for general information (health and wellness, ideas for & 3.57 & 2.68 \\
activities, research a topic) & 3.41 & 2.92 \\
Send or receive text messages (SMS) & 3.34 & 2.29 \\
Use social networking services (Facebook, Myspace, & & \\
Cafemom, etc.) & 2.99 & 2.30 \\
Read emailed newsletters (e.g., newsletters from school or & & \\
youth organizations) & 2.62 & 2.10 \\
Send or receive photos & 1.88 & 1.09 \\
Use instant messaging (AIM, MSN messenger, Yahoo! & & 1.01 \\
Chat, etc.) & 1.72 \\
Post on or read discussion boards or chat rooms & 1.71 & 0.90 \\
Read or comment on blogs & 1.54 & 0.86 \\
Watch, create, or share video files online (movies, TV, & & \\
home videos) & 1.49 & 0.70 \\
Participate in online classes, workshops, or webinars & 1.36 & 0.66 \\
Listen to, create, or share audio files online & 0.88 & 0.58 \\
Audio conference or make phone calls using the Internet & & \\
(e.g., Skype) & 0.81 & 0.49 \\
Use webcam or video conference & 0.67 & 0.30 \\
Create or maintain a website & 0.56 & 0.31 \\
Create, maintain, or write blogs & 0.42 & 0.16 \\
Create, maintain, or follow microblogs (Twitter) & & \\
\hline
\end{tabular}

${ }^{\mathrm{a}} 0=$ never; $1=$ less than once a month; $2=$ monthly; $3=$ weekly; $4=$ once a day; $5=$ several times a day.

${ }^{\mathrm{b}}$ Use of all activities in general are significantly more frequent than use for parenting, $p<.001$. 


\section{Purposes of New Media and Online Activities for Parenting}

The new media and online activity items were followed with a question asking parents how each activity "helps you as a parent." Parents were presented with a list of up to 15 possible reasons (e.g., "communicate with my child(ren)," "communicate with my child(ren)'s other parent") and were asked to select all of the ways the activity helped them fulfill their role as a parent. Parents were asked to respond "yes" or "no" to each item. We focus here on the use of new media and online activities for communicating with their child(ren), and their child(ren)'s other parent.

\section{Comfort}

A scale was computed by averaging parents' responses to eight questions regarding their comfort with technology $(\alpha=.756$; Bunz, 2004; Livingstone \& Bober, 2004). For example, participants were asked how comfortable they were with "using the Internet" and "downloading and saving an MP3." Participants responded on a five-point scale from $5=$ very comfortable, to $1=$ very uncomfortable. The mean comfort score was $4.23(\mathrm{SD}=.609)$.

\section{Attitude toward Technology Use}

Participants reported how much they agreed or disagreed with six statements regarding attitude toward technology and the Internet (Horrigan, 2007) using a five-point Likert scale $(1=$ Strongly disagree, $5=$ Strongly agree; e.g., "Make your life easier"; "Give you more control over your life"; "I like having so much information available"). A technology attitude score was computed by summing parents' responses to these items (range = $10-30 ; \alpha=.699)$. The mean attitude toward technology use score was 3.59 $(\mathrm{SD}=.625)$.

\section{Attitude toward Online Parenting Information}

Participants reported how much they agreed or disagreed with nine statements regarding attitude toward online parenting information (Cho, De Zuniga, Rojas, \& Shah, 2003; Madge \& O’Connor, 2002; Potosky, 2007) 
using a five-point Likert scale $(1=$ Strongly disagree, $5=$ Strongly agree; e.g., "The Internet has improved the way I get information about parenting"; $\alpha=.847)$. The mean attitude toward online parenting information score was $3.74(\mathrm{SD}=.567)$.

\section{RESULTS}

First, to better understand divorced parents use of technology, a series of descriptive analyses were computed. Most parents (81.9\%) reported having used a desktop computer, 137 parents $(77.8 \%)$ had used a laptop computer, 73 parents $(42.2 \%)$ had used a Blackberry, Palm, iPhone, or other personal digital assistant (PDA), 63 parents $(38.0 \%)$ had used a webcam, 58 $(35.2 \%)$ parents had used audio conference services or Skype, $102(60.4 \%)$ parents had used an iPod or other MP3 player, and 64 parents $(37.6 \%)$ had used a gaming console (e.g., Xbox, Playstation, Wii).

Parents accessed the Internet daily at home $(83.6 \%)$, at work $(77.7 \%)$, and from a handheld device $(29.7 \%)$. Internet access from public terminals was less frequent; $40 \%$ never accessed the Internet from public terminals and $32.1 \%$ did so less than once a month. When accessing the computer at home, $43.1 \%$ reported being the sole users of the computer and $55.6 \%$ reported using a shared computer. Only $15.2 \%$ of parents reported using the computer in a private area in the house, $45.5 \%$ reported using it in an open family area, and $39.4 \%$ reported both.

\section{DESCRIBING PARENTS' TECHNOLOGY USE}

First, parents reported their use of 17 new media and online activities in general and specifically for parenting (see Table 2). Parents reported using all activities in general significantly more frequently than their use of new media and online activities for parenting. The activities parents used most frequently in general were the same activities they used most frequently for parenting (e.g., email, text message, and social networking). Next, a series of $t$-tests, one-way ANOVA analyses, and correlations were computed to explore demographic differences in parents' use of new media and online activities for parenting (see Table 3). What is particularly striking is the lack of demographic differences that emerged. There were no differences in new media and online activity use by parent race. The only difference in 
Table 3. Demographic Differences in Parents' Use of New Media and Online Activities for Parenting.

\begin{tabular}{|c|c|c|c|c|c|}
\hline Activity $^{\mathrm{a}}$ & $\operatorname{Race}^{\mathrm{b}} t(d f)$ & $\operatorname{Area}^{\mathrm{c}} F(d f)$ & Income $^{\mathrm{d}} F(d f)$ & Parent Education $^{\mathrm{e}} F(d f)$ & Parent Age Pearson's $r$ \\
\hline Look for information & $-1.09(174)$ & $0.99(2,173)$ & $0.394(3,159)$ & $1.15(2,173)$ & $-0.169^{*}$ \\
\hline Make phone calls/Skype & $0.43(176)$ & $0.30(2,175)$ & $2.54(3,161)^{+}$ & $0.38(2,175)$ & -0.135 \\
\hline Use webcam & $-0.27(171)$ & $0.007(2,170)$ & $0.54(3,156)$ & $1.12(2,170)$ & -0.143 \\
\hline Use IM & $-1.29(171)$ & $0.032(2,170)$ & $0.17(3,156)$ & $0.062(2,170)$ & 0.128 \\
\hline Text message & $1.41(174)$ & $0.37(2,173)$ & $1.96(3,159)$ & $0.47(2,173)$ & -0.098 \\
\hline Discussion boards/chat rooms & $-1.62(174)$ & $0.38(2,173)$ & $0.94(3,159)$ & $0.38(2,173)$ & -0.131 \\
\hline Email & $-0.98(172)$ & $0.40(2,171)$ & $0.26(3,158)$ & $0.45(2,171)$ & 0.123 \\
\hline Read emailed newsletters & $-1.18(166)$ & $2.15(2,165)$ & $1.73(3,152)$ & $4.37(2,165)^{*}$ & -0.075 \\
\hline Send/receive photos & $1.07(162)$ & $1.28(2,161)$ & $0.56(3,148)$ & $0.26(2,161)$ & $-0.210^{* *}$ \\
\hline Share audio files & $-1.30(171)$ & $0.76(2,170)$ & $1.24(3,156)$ & $0.50(2,170)$ & -0.091 \\
\hline Share video files & $-0.40(171)$ & $0.41(2,170)$ & $0.39(3,157)$ & $0.18(2,170)$ & $-0.164^{*}$ \\
\hline Read/comment on blogs & $-1.38(173)$ & $1.50(2,172)$ & $0.23(3,158)$ & $0.14(2,172)$ & -0.105 \\
\hline Create/write blogs & $-1.22(174)$ & $2.18(2,173)$ & $4.05(3,159)^{* *}$ & $0.58(2,173)$ & -0.084 \\
\hline Microblog (Twitter) & $-0.41(175)$ & $1.34(2,174)$ & $1.85(3,160)$ & $0.72(2,174)$ & -0.070 \\
\hline Create/maintain website & $-0.69(170)$ & $1.39(2,169)$ & $3.45(3,155)^{*}$ & $0.028(2,169)$ & 0.047 \\
\hline Use SNS & $0.95(168)$ & $0.39(2,167)$ & $0.62(3,153)$ & $0.14(2,167)$ & -0.020 \\
\hline Take online classes & $-1 / 31(167)$ & $3.41(2,166)^{*}$ & $0.24(3,152)$ & $0.28(2,166)$ & -0.064 \\
\hline
\end{tabular}

$* p<.05 ; * * p<.01 ; * * * p<.001$

${ }^{+} p=.058$

${ }^{\mathrm{a}} 0=$ never; $1=$ less than once a month; $2=$ monthly; $3=$ weekly; $4=$ once a day; $5=$ several times a day.

$\mathrm{b}_{2}=$ White, $1=$ non-white.

${ }^{\mathrm{c}} 1=$ rural, $2=$ suburban, $3=$ urban.

${ }^{d} 1=$ less than $\$ 30,000,2=\$ 30,000-$ less than $\$ 50,000,3=\$ 50,000-$ less than $\$ 75,000,4=\$ 75,000-\$ 100,000$ or more).

${ }^{\mathrm{e}} 1=$ less than college, $2=$ college degree, $3=$ postgraduate training. 
rural, suburban, or metro status was the use of online classes $(F=3.41$ $(2,166), p=.035)$. While there was a significant main effect, post hoc analyses revealed no single group differences. The only difference by parent education was that parents with a college degree reported reading emailed newsletters significantly more frequently than parents without a college degree $(F=4.37(2,165), p=.014)$. For income, parents earning between $\$ 50,000$ and $\$ 75,000$ a year reported significantly more frequently creating/ writing blogs $(F=4.05(3,159), p=.008)$ and creating/maintaining a website $(F=3.45(3,155), p=.018)$ than parents earning between $\$ 30,000$ and $\$ 50,000$ a year. Parent age was negatively correlated with looking for information, sending and receiving photos and sharing video files, meaning that older parents did these activities less frequently.

Third, parents were asked how often they used these new media and online activities for communication with child(ren) and their child(ren)'s other parent (Table 4). Overall, at least half of parents reported supplementing their communication with their child(ren)'s other parent via technology. The most frequently used new media and online communication tools for communicating with the child's other parent were text message

Table 4. Parenting Activities Online.

\begin{tabular}{lccc}
\hline & $N$ & \multicolumn{2}{c}{$\begin{array}{c}\text { Parents Who Used It to } \\
\text { Communicate with: }\end{array}$} \\
\cline { 3 - 4 } & & Child(ren) Other's Parent & Child(ren) \\
\hline Parent activity (at least weekly) & 149 & $51.0 \%$ & $62.4 \%$ \\
Send or receive email & 112 & $52.7 \%$ & $69.6 \%$ \\
Use text messaging & 87 & $24.1 \%$ & $52.9 \%$ \\
Use social networking sites & 40 & $25.0 \%$ & $80.0 \%$ \\
$\begin{array}{l}\text { Use Instant Messaging (AIM, } \\
\text { MSN messenger, Yahoo! }\end{array}$ & & & \\
$\begin{array}{l}\text { Chat, etc.) } \\
\text { Parent activity (at least monthly) }\end{array}$ & 41 & $24.4 \%$ & $41.5 \%$ \\
$\begin{array}{l}\text { Watch, create, or share video files } \\
\text { Use audio conferencing or make } \\
\text { phone calls using Internet (Skype) }\end{array}$ & 29 & $24.1 \%$ & $58.6 \%$ \\
$\begin{array}{l}\text { Use webcam or video conference } \\
\text { Parent activity (ever) }\end{array}$ & 26 & $19.2 \%$ & $50.0 \%$ \\
Send or receive photos & 145 & $37.9 \%$ & $51.0 \%$ \\
\hline
\end{tabular}


$(52.7 \%)$, email $(51.0 \%)$, and sharing photos (37.9\%). Parents reported using all communication tools more frequently with their child(ren) than with their child(ren)'s other parent. The most frequent online communication tools used to communicate with child(ren) were instant messaging $(80 \%)$, text message $(69.6 \%)$, and email $(62.4 \%)$.

\section{ATTITUDES AND COMFORT}

Parents were then asked to report how comfortable they were doing different activities on the computer and Internet and were asked to report their attitudes toward using the Internet in general and for parenting (Tables 5 and 6). Overall parents felt very comfortable, and valued the Internet as a tool in giving them more control and information. Parents were also asked what makes the Internet difficult and reported concerns about viruses $(39.3 \%)$, worry about spyware or spam $(32.6 \%)$, and lack of time $(24.7 \%)$. Very few parents reported that limited access or equipment $(9.0 \%)$, cost of the Internet $(7.3 \%)$, or health problems $(2.2 \%)$ were barriers to Internet use. Overall, divorced parents reported high levels of comfort using technology, and reported that they used technology to support their parenting and enhance their communication with their coparent.

\section{DISCUSSION}

It can be extremely challenging for divorced parents to communicate with each other and maintain communication with their children, especially when the children are at the other parent's home. The limited research that does exist (Saini et al., 2013; Wolman \& Pomerance, 2012; Yarosh et al. 2009) suggests that technology can both improve coparent communication and the coparent relationship, but also make it worse (Chapman et al., 2015). Regardless, divorced parents are active technology users and are using technology in their role as coparents. Understanding how divorced parents are using technology for parenting and communication with the other parent enhances our ability to support families in the effective use of technology.

What stands out in these data is that parents are using technology and that extends into parenting and divorce parenting in particular. Parents do not adopt tools specifically for parenting, rather they use the technologies 
Table 5. Comfort Using Computers and the Internet.

\begin{tabular}{|c|c|c|c|c|c|c|}
\hline & \multicolumn{2}{|c|}{ I Never Do This } & \multicolumn{2}{|c|}{$\begin{array}{l}\text { Very Comfortable or } \\
\text { Comfortable }\end{array}$} & \multicolumn{2}{|c|}{$\begin{array}{c}\text { Very } \\
\text { Uncomfortable or } \\
\text { Uncomfortable }\end{array}$} \\
\hline & $N$ & $\%$ & $N$ & $\%$ & $N$ & $\%$ \\
\hline Using the Internet & 0 & $0.0 \%$ & 174 & $99.4 \%$ & 0 & $0.0 \%$ \\
\hline Using computers & 0 & $0.0 \%$ & 175 & $99.5 \%$ & 0 & $0.0 \%$ \\
\hline Setting up email account & 3 & $1.7 \%$ & 162 & $92.6 \%$ & 3 & $1.7 \%$ \\
\hline Sending an IM & 18 & $10.3 \%$ & 134 & $76.6 \%$ & 5 & $2.9 \%$ \\
\hline Downloading an $\mathrm{mp} 3$ & 30 & $17.3 \%$ & 93 & $53.8 \%$ & 20 & $11.6 \%$ \\
\hline Setting up filter for junk mail & 14 & $8.0 \%$ & 101 & $57.4 \%$ & 26 & $14.8 \%$ \\
\hline Getting rid of virus & 15 & $8.6 \%$ & 67 & $38.2 \%$ & 67 & $38.3 \%$ \\
\hline Fixing problem by myself & 15 & $8.5 \%$ & 66 & $37.5 \%$ & 61 & $34.7 \%$ \\
\hline
\end{tabular}


Table 6. Attitudes toward Using the Internet.

\begin{tabular}{|c|c|c|}
\hline & \multicolumn{2}{|c|}{ Agree or Strongly Agree } \\
\hline & $N$ & $\%$ \\
\hline $\begin{array}{l}\text { I'm usually successful at finding what I am looking } \\
\text { for when searching the Internet }\end{array}$ & 168 & $94.9 \%$ \\
\hline I get up-to-date information from the Internet & 156 & $88.6 \%$ \\
\hline $\begin{array}{l}\text { When using the Internet, I quickly find information } \\
\text { that I am looking for }\end{array}$ & 156 & $87.6 \%$ \\
\hline $\begin{array}{l}\text { The Internet has improved the way I get } \\
\text { information about parenting }\end{array}$ & 125 & $70.6 \%$ \\
\hline I find some parenting websites difficult to use & 23 & $13.2 \%$ \\
\hline $\begin{array}{l}\text { I can't find the sorts of parenting websites or } \\
\text { parenting information I'm interested in }\end{array}$ & 20 & $11.4 \%$ \\
\hline The parenting resources I find are too expensive & 16 & $9.0 \%$ \\
\hline $\begin{array}{l}\text { My connection or computer is too slow to find } \\
\text { parenting information }\end{array}$ & 14 & $8.0 \%$ \\
\hline $\begin{array}{l}\text { The parenting information I find is poor or } \\
\text { questionable }\end{array}$ & 10 & $5.7 \%$ \\
\hline It takes too much time to get parenting information & 6 & $3.4 \%$ \\
\hline $\begin{array}{l}\text { The parenting information I find is difficult } \\
\text { to understand }\end{array}$ & 4 & $2.3 \%$ \\
\hline $\begin{array}{l}\text { The software I use isn't good enough to find } \\
\text { parenting information }\end{array}$ & 4 & $2.3 \%$ \\
\hline \multicolumn{3}{|c|}{ Thinking about all the technologies you use, overall would you say these devices: } \\
\hline Make your life easier & 161 & $90.5 \%$ \\
\hline I like having so much information available & 148 & $83.7 \%$ \\
\hline Give you more control over your life & 119 & $67.2 \%$ \\
\hline Make your life more complicated & 63 & $36.0 \%$ \\
\hline Make you feel overloaded & 62 & $34.8 \%$ \\
\hline Give you less control over your life & 20 & $11.3 \%$ \\
\hline
\end{tabular}

that are present in their everyday life for parenting. Our findings further suggest that divorced coparents use technology much like other parents, to communicate about parenting, to communicate with their children, and to find information and resources to support their parenting (Dworkin et al., 2013). In fact, parenting is a big part of how parents are using new media and a big contributor to what they are doing online. The ability to 
distinguish general technology use from technology use for parenting provides a more accurate and complete picture of how parents are using technology. Future initiatives should focus on supporting divorced parents and their use of technology to continue to refine the practices where divorced parents report communication difficulties.

Consistent with the uses and gratification perspective, these data reveal that parents are active and dynamic users of technology for parenting, and they are selective in which tools they use for which task. For instance, use of technology for parenting may be more limited to tools that are text based, asynchronous, and do not include visual and audio features. They use technologies parents already have access to, which do not need to be downloaded or installed or updated. This removes barriers for parents to access the tool to use. Less "intimate" direct communications like email and text are reported as being more helpful for communicating with the other parent. Tools that include more intimate forms of interaction, such as video interaction, or time synchronous communications, may be less useful both because they are more intimate and because they require more advance cooperation (e.g., adding someone into your Skype network). Those more intimate tools are helpful for communicating with children but less so for communicating with the coparent.

Research on technology use would suggest that technology use is dependent on a match between issue and users. Findings of the current study suggest that comfort with technology was not associated with whether or not parents were using technology to communicate with the other parent or the children; however, parents reported being more comfortable with easy tasks and less comfortable with harder tasks. Future research should examine parent technology use in the context of particular issues, for instance, examining differences between communicating around child transportation versus more sensitive topics such as child discipline.

\section{LIMITATIONS AND FUTURE DIRECTIONS}

The current study provides a descriptive look at divorced parent's use of technology to communicate with their coparent and their children. Although limited in sample size, this preliminary look helps set the stage for larger studies with more complex research questions and data analysis. As is common in studies of technology use, the current study uses measures of which device, with whom, and how often. However, we did not capture 
the reasons for communicating or the content of the communication. In addition, with the rapid changes in technology use, research is particularly challenged to keep up with the rapid changes. The current study focused on type of media, for example, social networking sites rather than Facebook in particular, providing a broad look at parents online behavior. Future research should use innovative methodologies and measures to better understand the use of technology and the use of specific technologies and tools to negotiate boundaries between coparents who are living apart. These data only assessed one parent's comfort, attitudes, and use. Because effective use of new media and online communication is dependent upon the participation of both parties, future research must consider the other parents use of technology and their comfort as well. Further, it is essential to better understand which technology supports what type of communication and decision making for which parents. For instance, our limited findings regarding demographic differences are likely a function of sample size. A larger, more diverse sample might reveal different patterns of divorced parents' technology use.

\section{IMPLICATIONS}

Technology allows for asynchronous communication, staying up to date, making plans, and making decisions with minimal interaction, and thus maintaining boundaries. Our evidence suggests technology could help parents find areas of agreement around their children's lives in a less contentious environment. More specifically, it seems likely that the most conflictual coparents could perhaps benefit most from well-designed technologies that support mutual decision making in an environment that allows for maintaining boundaries.

There are currently several synchronous technology-based programs to help coparents with shared calendars that have proven helpful for parents to make decisions regarding involvement in activities and supporting positive perceptions of the other parent, but can have the risk of reducing privacy (Odom et al., 2010). One area where divorcing and separating parents have reported difficulty, especially those who are in high conflict, is in creating a parenting plan. There is currently no technology product on the market with this capacity, although parenting plans are mandated in most jurisdictions. For divorcing couples, the need for a parenting plan precedes the need for communication technologies like those described above, and 
thus provides an ideal intervention point for technology assisted programs. Having asynchronous communication technology that can help parents create a plan while not having to physically come together would save them time, energy, money spent on attorneys and would help to maintain boundaries between parents, especially during the early period of separation when parenting plans likely still need to be developed.

\section{ACKNOWLEDGMENT}

This study was supported by the Minnesota Agricultural Experiment Station with a grant to the first author.

\section{REFERENCES}

Afifi, T. D., \& McManus, T. (2006). Communal coping dilemmas in post-divorce families: Introducing meaning back into coping. In R. M. Dailey \& B. A. LePoire (Eds.), Applied interpersonal communication matters: Family, health, and community relations (pp. 67-89). New York, NY: Peter Lang.

Ahrons, C. R. (2007). Family ties after divorce: Long-term implications for children. Family Process, 46(1), 53-65.

Alberts, J. K., Yoshimura, C. G., Rabby, M., \& Loschiavo, R. (2005). Mapping the topography of couples' daily conversation. Journal of Social and Personal Relationships, 22(3), 299-322.

Allen, K., \& Rainie, L. (2002). Parents online. Pew internet and American Life Project. Retrieved from http://www.pewinternet.org/ $/$ media/Files/Reports/2002/PIP_Parents_ Report.pdf.pdf

Beckmeyer, J., Coleman, M., \& Ganong, L. (2014). Post-divorce coparenting typologies and children's adjustment. Family Relations, 63, 526-537.

Blackburn, C., \& Read, J. (2005). Using the internet? The experiences of parents of disabled children. Child: Care, Health and Development, 31(5), 507-515.

Buchanan, C. M., Maccoby, E. E., \& Dornbusch, S. M. (1996). Adolescents after divorce. Cambridge, MA: Harvard University Press.

Bunz, U. (2004). The Computer-Web-Email (CEW) fluency scale: Development and validation. International Journal of Human-Computer Interaction, 17(4), 479-506.

Chapman, A., Ganong, L. H., \& Coleman, M. (2015). Divorced coparents' use of communication technology. In Z. Yan (Ed.), Encyclopedia of mobile phone behavior (Vol. 1, 2, \& 3). Hershey, PA: IGI Global.

Cho, J., De Zuniga, H. G., Rojas, H., \& Shah, D. V. (2003). Beyond access: The digital divide and Internet uses and gratifications. It \& Society, 1(4), 46-72.

Dworkin, J., Connell, J., \& Doty, J. (2013). A literature review of parents' online behavior. Cyberpsychology: Journal of Psychological Research on Cyberspace, 7, 2. 
Ganong, L., Coleman, M., Jamison, T., \& Feistman, R. (2015). Divorced mothers' coparental boundary maintenance after parents re-partner. Journal of Family Psvchology, 29(2), 221-231.

Ganong, L. H., Coleman, M., Feistman, R., Jamison, T., \& Markham, M. S. (2012). Communication technology and postdivorce coparenting. Familv Relations, 61, 367-409.

Ganong, L. H., Coleman, M., Markham, M., \& Rothrauff, T. (2011). Predicting postdivorce coparental communication. Journal of Divorce \& Remarriage, 52(1), 1-18.

Goldsmith, D. J., \& Baxter, L. A. (1996). Constituting relationships in talk a taxonomy of speech events in social and personal relationships. Human Communication Research, 23(1), 87-114.

Grant, I. C. (2005). Young peoples' relationship with online marketing practices: An intrusion too far? Journal of Marketing Management, 21, 607-623.

Horrigan, J. (2007). A typology of information and communication technology users. Pew Internet and American life project. Retrieved from http://www.pewInternet.org/Reports/ 2007/A-Typology-of-Information-and-Communication-Technology-Users/Summary-ofFindings.aspx?view $=$ all

Laliker, M. K., \& Lannutti, P. J. (2014). Remapping the topography of couples' daily interactions: Electronic messages. Communication Research Reports, 31(3), 262-271.

Lee, S. J., \& Chae, Y. G. (2007). Children's internet use in a family context: Influence on family relationships and parental mediation. CyberPsychology \& Behavior, 10(5), 640-644.

Livingstone, S., \& Bober, M. (2004). UK children go online: Surveying the experiences of young people and their parents. [online]. London: LSE Research Online. Retrieved from http:// eprints.1se.ac.uk/archive/00000395

Maccoby, E. E., Depner, C. E., \& Mnookin, R. H. (1990). Coparenting in the second year after divorce. Journal of Marriage and the Familv, 52, 141-155.

Madge, C., \& O'Connor, H. (2002). On-line with e-mums: Exploring the internet as a medium for research. Area, 34(1), 92-102.

Miller, A. E. (2009). Face concerns and facework strategies in maintaining postdivorce coparenting and dating relationships. Southern Communication Journal, 74(2), 157-173.

Odom, W., Zimmerman, J., \& Forlizzi, J. (2010, August). Designing for dynamic family structures: Divorced families and interactive systems. In Proceedings of the 8th ACM conference on designing interactive systems (pp. 151-160). New York: Association for Computing Machinery.

Potosky, D. (2007). The Internet knowledge (iKnow) measure. Computers in Human Behavior, 23(6), 2760-2777.

Rodriguez, S. R. (2014). "We'll only see parts of each other's lives": The role of mundane talk in maintaining nonresidential parent-child relationships. Journal of Social and Personal Relationships, 31(8), 1134-1152.

Rubin, A. M. (2002). The uses-and-gratifications perspective of media effects. In J. Bryant \& D. Zillman (Eds.), Media effects: Advances in theory and research (pp. 525-548). Mahwah, NJ: Lawrence Erlbaum.

Ruggiero, T. E. (2000). Uses and gratifications theory in the 21 st century. Mass Communication \& Societv, 3(1), 3-37.

Saini, M., Mishna, F., Barnes, J., \& Polak, S. (2013). Parenting online: An exploration of virtual parenting time in the context of separation and divorce. Journal of Child Custodv, 10(2), 120-140. 
Sandler, I., Miles, J., Cookston, J., \& Braver, S. (2008). Effects of father and mother parenting on children's mental health in high-and low-conflict divorces. Family Court Review, 46(2), 282-296.

Schrodt, P., Braithwaite, D. O., Soliz, J., Tye-Williams, S., Miller, A., Normand, E. L., \& Harrigan, M. M. (2007). An examination of everyday talk in stepfamily systems. Western Journal of Communication, 71(3), 216-234.

Subrahmanyam, K., \& Greenfield, P. (2008). Online communication and adolescent relationships. The Future of Children, 18(1), 119-146.

Vespa, J., Lewis, J. M., \& Kreider, R. M. (2013). America's families and living arrangements: 2012. Current population reports (pp. 20-570). Washington, DC: US Census Bureau. Retrieved from www.census.gov/prod/2013pubs/p20-570.pdf

Wolman, R., \& Pomerance, R. (2012). Telepresence technology in divorce and separation. Open Access Journal of Forensic Psychology, 4, 51-68.

Yarosh, S., Chieh, Y., \& Abowd, G. D. (2009). Supporting parent-child communication in divorced families. International Journal of Human-Computer Studies, 67(2), 192-203.

Ybarra, M. L., \& Mitchell, K. J. (2004). Youth engaging in online harassment: Associations with caregiver-child relationships, internet use, and personal characteristics. Journal of adolescence, 27(3), 319-336. 